\title{
A design methodology to reduce the embodied carbon of concrete buildings using thin-shell floors
}

\author{
Will Hawkins ${ }^{\mathrm{a}, *}$, John Orr ${ }^{\mathrm{a}}$, Tim Ibell ${ }^{\mathrm{b}}$, Paul Shepherd ${ }^{\mathrm{b}}$ \\ ${ }^{a}$ Department of Engineering, University of Cambridge, UK \\ ${ }^{b}$ Department of Architecture and Civil Engineering, University of Bath, UK
}

\begin{abstract}
This paper explores the potential of thin concrete shells low-carbon alternatives to floor slabs and beams, which typically make up the majority of structural material in multi-storey buildings. A simple and practical system is proposed, featuring pre-cast textile reinforced concrete shells with a network of prestressed steel tension ties. A non-structural fill is included to provide a level top surface. Building on previous experimental and theoretical work, a complete design methodology is presented. This is then used to explore the structural behaviour of the proposed system, refine its design, and evaluate potential carbon savings.

Compared to flat slabs of equivalent structural performance, significant embodied carbon reductions (53-58\%) are demonstrated across spans of 6-18 m. Self-weight reductions of $43-53 \%$ are also achieved, which would save additional material in columns and foundations. The simplicity of the proposed structure, and conservatism of the design methodology, indicate that further savings could be made with future refinements.

These results show that considerable embodied carbon reductions are possible through innovative structural design, and that thin-shell floors are a practical means of achieving this.
\end{abstract}

Keywords: Concrete shells, Structural optimisation, Textile reinforced concrete, Floor structures, Embodied carbon, Low-carbon buildings

\section{Introduction}

The production of Portland cement has nearly trebled over the past 20 years [1], and is now estimated to contribute $6-8 \%$ of global carbon emissions $[2,3]$. The equivalent figure for steel is $9 \%$ [4], with approximately half of this attributed to the construction industry [5].

$5 \quad$ Building construction is a major driver of material consumption, accounting for $83 \%$ of UK cement use [6] and one-third of global steel demand [7]. With the worldwide floor area of buildings predicted to double over the next 40 years [8], this represents a major barrier to decarbonisation of the global economy. Improvements in material production efficiency alone will be insufficient to counteract increased consumption [9, 10]. Somehow, a reduction in demand must be achieved, and structural engineers therefore have a vital role to play. This is increasingly - being recognised across the industry, with many UK design firms now officially declaring a climate and biodiversity emergency [11]. However, this intent cannot be acted upon without appropriate tools.

Floors contain the majority of a typical building's structural material and embodied carbon $[12,13,6]$, making them a primary target for efficiency gains. A common floor construction typology is the reinforced concrete flat slab, favoured for its simple formwork requirements, low structural depth and architectural flexibility. For design

\footnotetext{
* Corresponding author

Email address: wjh35@cam.ac.uk (Will Hawkins)
} 
purposes, flat slabs are assumed to act in shear and bending. The majority of concrete is therefore assumed cracked, making no strength contribution and necessitating the use of large quantities of steel reinforcement, which are further increased through rationalisation for construction simplicity [14]. Alternatives to flat slabs have been previously shown to offer material efficiency gains. Embodied energy savings of $8 \%$ have been demonstrated through the introduction of column heads [15], 17-22\% using ribs and beams [16] and 28-41\% through post-tensioning [15]. In each of these cases, the primary structural actions remain bending and shear.

In tests conducted within completed buildings, Ockleston [17] found that the ultimate strength of flat slabs can be up to five times greater than that predicted using an upper-bound yield-line theory. This is due to an arching effect known as compressive membrane action, which arises from the lateral restraint provided by neighbouring slabs. It is therefore hypothesised that an alternative approach to concrete floor design, utilising membrane action, could achieve significant material savings over bending structures.

Vaults are common in historic masonry construction, and also feature in current research into lightweight concrete floors. Single-spanning textile reinforced concrete (TRC) barrel vaults with vertical stiffeners have been developed by May et al. [18], with a span of $4.5 \mathrm{~m}$ and mass of $260 \mathrm{~kg} / \mathrm{m}^{2}$ (not including supporting beams). By comparison, an equivalent $170 \mathrm{~mm}$ thick flat slab, calculated according to the methodology described in Section 5.1 of this paper, has a mass of $425 \mathrm{~kg} / \mathrm{m}^{2}$. Reducing weight and concrete volume has a direct influence on embodied carbon, and can lead to further savings in columns and foundations. However, the vaulted system uses fine-grained concrete of $80 \mathrm{MPa}$ characteristic strength, which could have an embodied carbon nearly three times greater than that required by the slab [19]. The use of carbon fibre reinforcement is also likely to further increase embodied carbon compared to steel [20]. Liew et al. [21] and López et al. [22] describe a double-spanning vault with stiffening ribs projecting from the shell to form a level top surface, with a mass of $119 \mathrm{~kg} / \mathrm{m}^{2}$ over a span of $2.80 \mathrm{~m}$. In this case, the self-compacting fibre-reinforced concrete also has an embodied carbon three times greater than a typical mix [23], again counteracting the carbon savings made through weight reduction.

Tile-vaulting is an example of a thin-shell floor system utilising low-carbon materials, as famously demonstrated by the Guastavino Company in the early $20^{\text {th }}$ century [24]. More recently, this technique has been used to create unreinforced vaulted floors from stone and cement stabilised soil [25, 26]. However, the manual construction process is labour intensive, making large-scale application uneconomical in the modern industry. To be effective, a sustainable floor system must not only be structurally efficient, but should also be compatible with an economic construction process and avoid using carbon-intensive materials.

This paper begins by introducing a proposed structural system and corresponding design methodology, building upon previous publications $[27,28,29,30]$, which is verified through comparison with experimental tests. Once established, this methodology is used to further refine the design and compare its performance with flat slabs, enabling embodied carbon savings to be quantified.

\section{Design methodology}

\subsection{Proposed structural system}

In the proposed system, pre-cast TRC shells of uniform thickness span between columns, as shown in Figure 1. The two-way spanning shells consist of a single surface, without stiffeners, enabling the use of single-sided formwork. Services can also be integrated within the structural depth without obstruction, both above and below the shell.

Although the shell is designed to act primarily in compression, reinforcement is required to increase tensile capacity and provide robustness. The flexibility of textile reinforcement is well-suited to forming curved geometries, and lack of durability cover requirements leads to thinner sections compared to an equivalent steel mesh. 


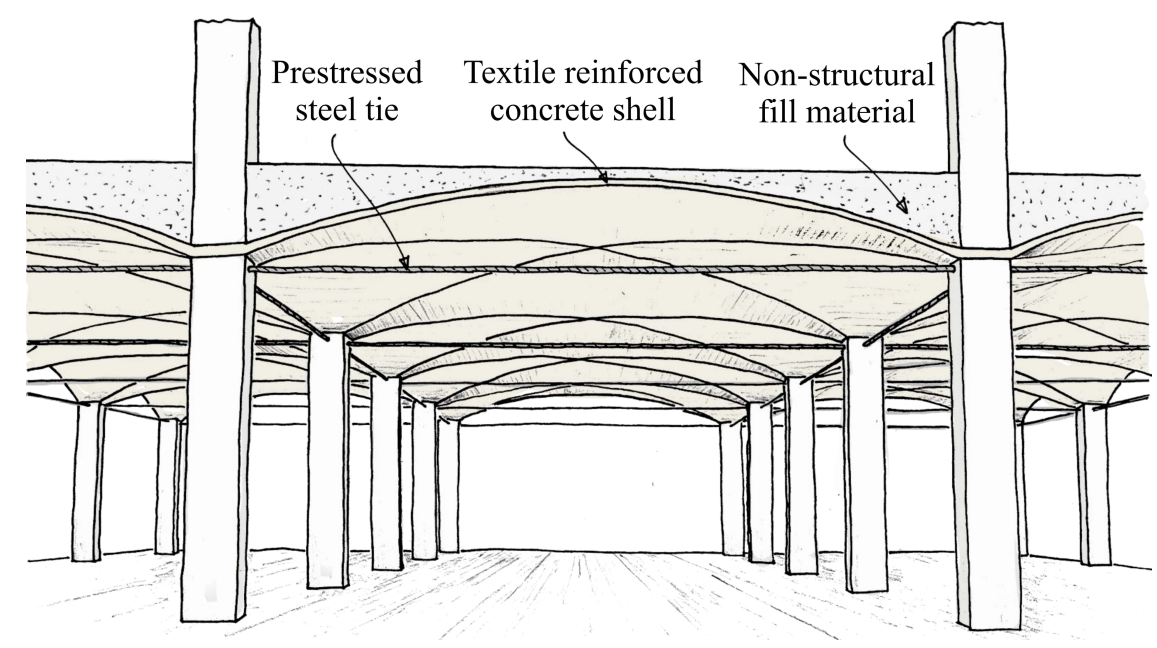

Figure 1: Layout of the proposed thin-shell flooring system.

A variety of shell geometries have been investigated in previous studies [27, 30], including hypars, spherical patches, and those form-found using dynamic relaxation. Groin vaults, as pictured in Figure 1, were identified as having a strong structural performance across deflection, vibration and buckling criteria. Formwork construction is also greatly simplified for these singly-curved, developable surfaces.

A network of steel ties counter the horizontal thrust from the shallow vaults by providing lateral restraint of high stiffness. Prestressing is also used to minimise deflections and bending forces within the shell.

Above the pre-cast shells, a fill material is used to create a level floor surface and distribute loads onto the shell beneath. In addition, the fill provides vibration damping, thermal insulation and acoustic absorption. In a previous study [29], two prototype shells were constructed and tested, with and without a foamed concrete fill of $800 \mathrm{~kg} / \mathrm{m}^{3}$ density. The inclusion of the fill was found to have only a small effect on strength and stiffness, and can therefore be conservatively ignored in analysis. Despite its low density, the cement content of foamed concrete is high [31, 32], and can therefore contribute significantly to the total embodied carbon of the system [30]. As a result, recycled aggregate is proposed as a low-carbon, low-cost and widely available alternative in this paper.

\subsection{Geometry definition}

Figure 2 shows parameters describing the geometry of the proposed system. The overall shell dimensions are given by the span $(l)$ and the column-interface width $(w)$. The shell height $(h)$, thickness $(t)$ and tie diameter $(d)$ also dictate the total volume of materials used. The TRC section features two layers of textile reinforcement, each with a cross-section area of $A_{t}$ at a cover depth of $c$. For manufacturing simplicity, the reinforcement is uniform throughout the shell.

The groin vault profile is a Bézier curve defined by the non-dimensional parameters $a$ and $b$. Despite using only two parameters, this strategy was found to create an almost unrestricted design space; in a preliminary study, the Bézier curve could match circular, parabolic and catenary target curves to within $0.05 \mathrm{~mm}$ accuracy over a span of $8 \mathrm{~m}$.

Along with the tie pre-strain $\varepsilon$, the parameters $a$ and $b$ have little influence on total material quantities and are therefore set to maximise efficient operation of the shell for any given design. The fitness parameter used to guide this optimisation process is the envelope of maximum bending strain energy over every loading scenario considered (these are discussed in Section 2.4). It has been shown previously [27, 30] that minimising bending strain energy has positive implications for structural performance, by maximising stiffness, natural frequency and buckling resistance 


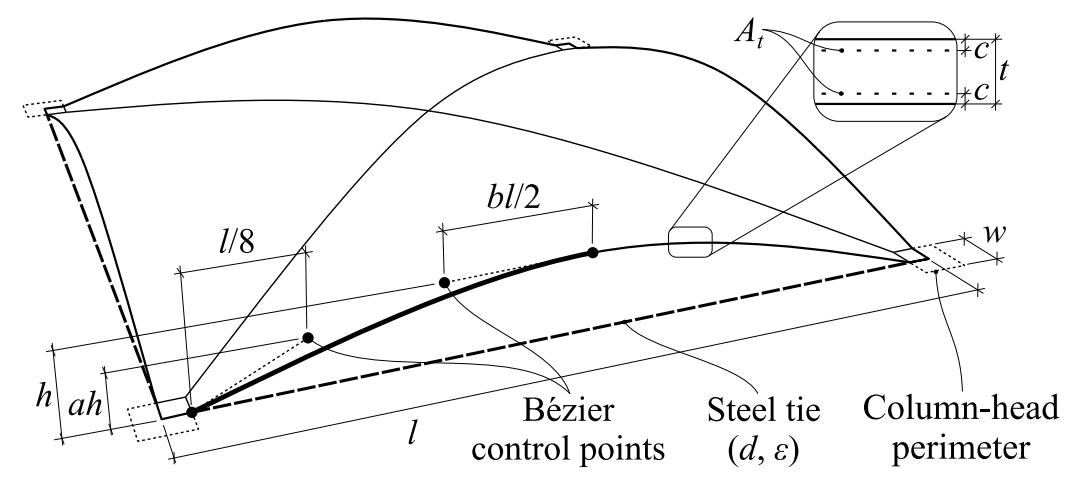

Figure 2: Geometric design variables for a square internal column bay.

whilst reducing the strength requirements of the TRC section and, correspondingly, material quantities. The fitness

landscape is smooth across these three parameters $(a, b$ and $\varepsilon$ ), with a single global minimum, ensuring reliable optimisation [29].

\subsection{Structural analysis}

Linear finite element (FE) analysis was used to calculate shell forces and deformation. A linear model significantly reduces computation time compared to a more detailed non-linear analysis, and the complexity of the TRC material model, therefore enabling simpler design exploration and optimisation. However, a linear analysis ignores the effects of concrete cracking and crushing, as well as changes in geometry. These have been previously shown to have only a minor influence on the predicted deformation in this application, through a direct comparison between linear and non-linear models [30]. Buckling also cannot be assessed by a linear model, although again this has been shown not to be critical in this application in previous publications, using both non-linear FE analysis and physical testing [29, 30]. Linear analysis ignores redistribution of peak forces caused by cracking and crushing, which is conservative in the context of the lower-bound design approach described in Section 2.5 of this paper.

In the FE model, the shell is meshed into regular triangular plate elements and analysed using Karamba [33]. The mass of the fill material is included as a dead load, but its contribution to stiffness and load-spreading is conservatively ignored. The FE model includes a single column bay, which is assumed to be structurally isolated from its neighbours. The nodes within each shell-column interface are constrained to more rigidly together such that the column section does not deform. These groups of nodes are fixed vertically but free to slide horizontally. This ignores the lateral stiffness of columns whilst including a rotational restraint, conservatively maximising bending moments in the shell. In all models, the concrete has a Poisson's ratio of 0.2 and the ties a Young's modulus of 210GPa.

\subsection{Loading and deflection criteria}

Dead and live loads are variously combined for ultimate (ULS) and serviceability (SLS) limit states according to BS EN 1991-1-1 [34]. For the investigations of this paper, the assumed floor loads include a superimposed dead load (SDL) of $1.0 \mathrm{kN} / \mathrm{m}^{2}$ for finishes and services, plus a $3.5 \mathrm{kN} / \mathrm{m}^{2}$ live load accounting for typical office use in the UK $\left(2.5 \mathrm{kN} / \mathrm{m}^{2}\right.$ plus partitions of $\left.1.0 \mathrm{kN} / \mathrm{m}^{2}\right)$. Point loads are not considered in this investigation, having previously been shown not to influence the design of the shells [30].

Two load combinations are used for ULS design: unfavourable (maximum) and favourable (minimum). These can, in principle, be distributed in any arrangement. Each part of the structure should therefore be designed for the worst-case loading pattern, and these are not immediately obvious for a curved shell surface. A comprehensive 
approach to this problem might be to construct influence surfaces for each region of the structure, analysing in-turn

the effect of a point load applied at every location [35]. However, Timoshenko and Woinowsky-Krieger [36] note the similarities between influence surfaces and natural vibration modes for irregular plates. The load patterns considered in this paper, as illustrated in Figure 3, were therefore chosen using this approach. Patterns 1 and 2 correspond to the first vibration mode of a typical groin vault, whilst the subsequent patterns represent increasingly higher modes. All of these patterns are considered simultaneously for ULS design, with the worst-case governing in each region of the shell.
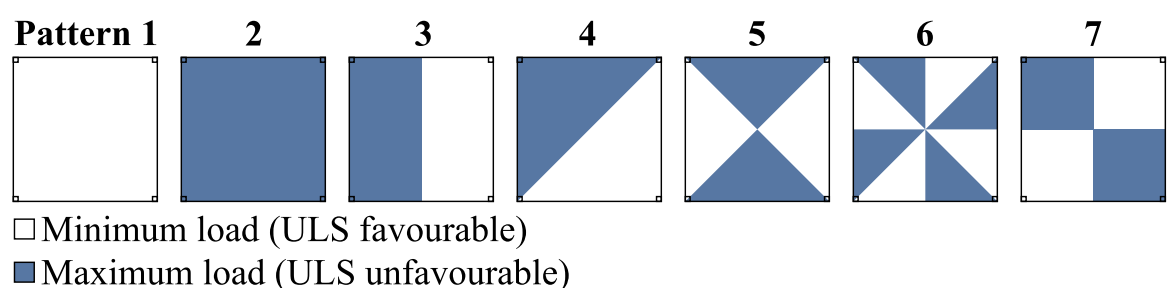

$\square$ Maximum load (ULS unfavourable)

Figure 3: Live load patterns used in ULS design, based on natural vibration modes.

Two serviceability requirements are also considered in this paper. Firstly, the total deflection including uplift caused by tie pre-strain $\left(\delta_{\text {total }}\right)$, and secondly that due to the live load only $\left(\delta_{\text {live }}\right)$. These are subject to limits of $\delta_{\text {total }} \leq l / 200$ and $\delta_{\text {live }} \leq l / 360$ as commonly recommended for composite floors [37]. The effects of creep in the TRC shell are accounted for using a simplified approach whereby the Young's modulus of concrete is reduced for long-term loadings ( $100 \%$ dead plus $30 \%$ live) by a factor of $(1+\varphi)$ [38]. The creep coefficient $(\varphi)$ depends on the relative humidity, thickness of the concrete element, type of cement, age of loading, aggregate type and concrete strength. In this investigation, a constant creep coefficient of $\varphi=2.5$ is assumed in all cases. This is the long-term value for a $50 \mathrm{~mm}$ thick shell of C32/40 concrete, exposed on one side to an indoor environment of $50 \%$ relative humidity, loaded 28 days after casting, and was calculated according to BS EN 1992-1-1 [38].

\subsection{TRC section design}

The TRC section is specified to provide sufficient strength under combined axial and bending forces throughout the shell, using a lower-bound ULS design approach. The strength utilisation is calculated from an analytical failure envelope developed in previous work by the authors [28]. This is an extension of the methodology proposed by Scholzen et al. [39], and is derived from stress-strain curves for both concrete and reinforcement. The required material parameters therefore include the concrete compressive strength $\left(f_{c}\right)$, the reinforcement stiffness $\left(E_{t}\right)$ and the reinforcement tensile strength in the composite section $\left(f_{t c}\right)$. The local reinforcement strength depends on the direction of loading relative to reinforcement [40,39], and this is accounted for in the model. Within each finite element, the critical utilisation is the maximum from all loading patterns in Figure 3.

\subsubsection{TRC utilisation at column interface}

The shell-column interface is a critical region for ULS design due to a concentration of compressive forces. In this region, the peak elemental forces of the FE model are mesh-dependent, and therefore cannot reliably be used for design. This is because the re-entrant geometry and a large local reaction force create a stress singularity [27, 30]. In reality, these peaks will be attenuated by non-rigid supports and redistributed through localised cracking or softening. A new method of interpreting the FE results has therefore been devised to enable reliable design of the TRC section. In the proposed model, nodal reactions are converted to equivalent uniformly distributed loads, as shown in Figure 4. 


\section{Reaction forces (FE model)}

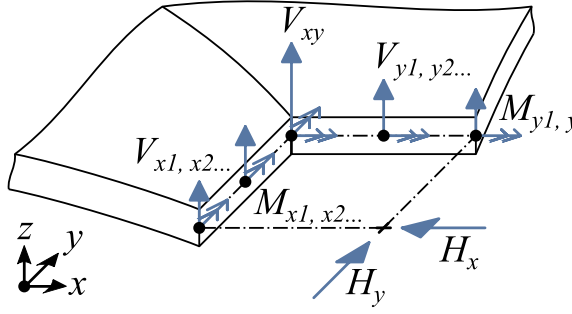

\section{Equivalent uniform shell forces}

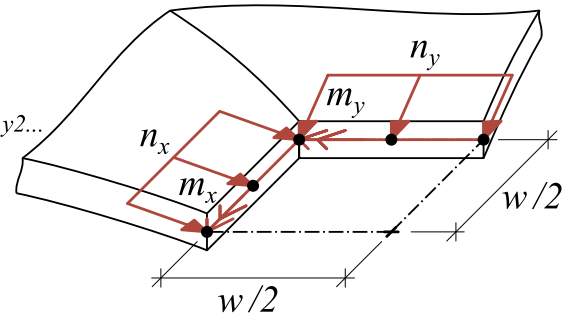

Figure 4: Reaction forces and corresponding uniformly distributed forces at the shell-column interface.

The uniform axial forces per unit length $\left(n_{x}\right.$ and $\left.n_{y}\right)$ are the vector sums of the corresponding tie forces $\left(H_{x}\right.$ and $\left.H_{y}\right)$ and the vertical nodal reactions $\left(V_{x}\right.$ and $\left.V_{y}\right)$, distributed over the column edge widths $(w)$, as shown in Equation 1 . The reaction at the inside corner $\left(V_{x y}\right)$ is shared equally between the two faces.

$$
\begin{aligned}
& n_{x}=\frac{2}{w} \sqrt{\left(\sum V_{x}+\frac{V_{x y}}{2}\right)^{2}+H_{x}^{2}} \\
& n_{y}=\frac{2}{w} \sqrt{\left(\sum V_{y}+\frac{V_{x y}}{2}\right)^{2}+H_{y}^{2}}
\end{aligned}
$$

Similarly, the moments per unit length $\left(m_{x}\right.$ and $\left.m_{y}\right)$ are the sum of corresponding nodal values $\left(M_{x}\right.$ and $\left.M_{y}\right)$ :

$$
\begin{aligned}
& m_{x}=\frac{2}{w} \sum M_{x} \\
& m_{y}=\frac{2}{w} \sum M_{y}
\end{aligned}
$$

This is a lower-bound approach, and as such it relies on the material being able to redistribute forces in a ductile manner. Similar assumptions are commonly made to model the crushing of concrete in beams [41], and Ibell and Burgoyne [42] also used an analogous approach for predicting the capacity of prestressing tendon anchorage zones.

\subsubsection{Minimum reinforcement}

Since the shells act primarily in compression, the reinforcement requirement for the TRC section is low compared to more common, tension-critical applications such as thin-walled bending elements, cantilever shells or strengthening of existing beams [43]. This might lead to issues of under-reinforcement where the tensile capacity of the reinforcement may be smaller than that of the concrete, creating a risk of brittle failure.

For steel-reinforced concrete, BS EN 1992-1-1 [38] defines the minimum reinforcement in proportion to the ratio

of the tensile strengths of the concrete $\left(f_{c t m}\right)$ and reinforcement $\left(f_{t c}\right)$. A similar approach is proposed in this case, whereby the minimum reinforcement area in each of the two layers $\left(A_{t, \min }\right)$ has the same tensile strength as half of the concrete section, according to Equation 3:

$$
A_{t, \min }=\frac{f_{c t m}}{f_{t c} / \sqrt{2}} \frac{t}{2}
$$

Note that the textile strength is conservatively reduced by a factor of $\sqrt{2}$, which assumes equal reinforcement in both the $0^{\circ}$ and $90^{\circ}$ directions with cracking occurring at a worst-case angle of $45^{\circ}$ relative to these (according to

Scholzen et al. [39]). In this paper, $f_{c t m}$ is calculated as a function of concrete compressive strength in accordance with BS EN 1992-1-1 [38]. 


\section{Verification of design methodology}

The design, construction and testing of two prototypes has been detailed in previous publications [29, 30]. In this section, the same scenario is modelled using the strength design methodology proposed here, in order to assess its reliability.

\subsection{Physical testing}

Both shell specimens were quarter-scale models of the full-scale system, and were $18 \mathrm{~mm}$ thick, spanned $2 \mathrm{~m}$ and featured two layers of alkali-resistant (AR) glass fibre textile reinforcement. However, only one shell included the foamed concrete fill. Each was tested to destruction under an asymmetric load (Pattern 3 in Figure 3). Using four hydraulic jacks, the load over one half of the shell was held constant at $3.75 \mathrm{kN} / \mathrm{m}^{2}$ (the minimum ULS value), and increased to failure over the other half. The shell without fill, shown in Figure 5, sustained a maximum load of $14.6 \mathrm{kN} / \mathrm{m}^{2}$, whilst a higher load of $16.2 \mathrm{kN} / \mathrm{m}^{2}$ was carried by the second shell with fill included.

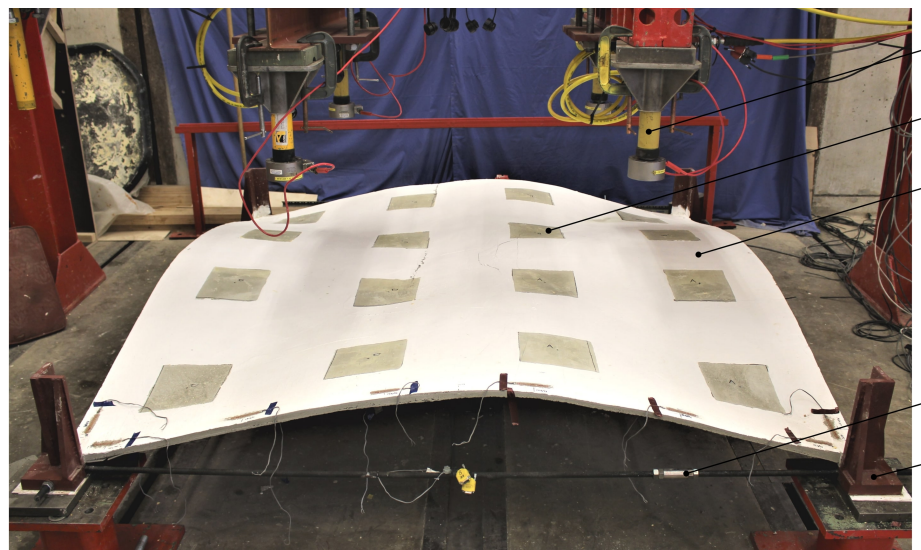

Hydraulic jack

Loading patch

TRC shell

(18mm thick)

Figure 5: Prototype shell (without fill) after testing to a maximum asymmetric load of $14.6 \mathrm{kN} / \mathrm{m}^{2}$, as previously described by Hawkins et al. [29].

\subsection{Predicted failure load}

The proposed strength design methodology was used to predict the asymmetric load at failure, using the geometry and material parameters given in Table 1 . The concrete strength $\left(f_{c}\right)$ is the average value from six prism tests. The reinforcement stiffness $\left(E_{t}\right)$ was measured through tests on the textile only, whilst the tensile strength $\left(f_{t c}\right)$ was determined from tests on TRC specimens matching the shells [30]. Variation between the warp and fill reinforcement directions arise due to differences in yarn construction and weave patterns.

The predicted failure load is $11.5 \mathrm{kN} / \mathrm{m}^{2}$, at which point the maximum utilisation along one of the shellcolumn interfaces is equal to 1.00. Figure 6a shows the distribution of strength utilisation at this load. The maximum elemental utilisation is 1.69 , occurring at the re-entrant corner at the shell-column interface. This value is mesh-dependent and therefore superseded by the value across the full interface surface which has a much lower mesh-sensitivity; increasing the number of elements by a factor of four resulted in less than a $1 \%$ change in predicted section utilisation.

Figure $6 \mathrm{~b}$ compares the local pairs of axial and bending forces with the failure envelopes for the TRC section in the $0^{\circ}$ (warp), $45^{\circ}$ and $90^{\circ}$ (fill) reinforcement directions. At the critical shell-column interface, the local shell forces sit at the region of the failure envelope with highest bending strength, where the level of compression is most favourable. This indicates that the TRC section is acting efficiently. 
Table 1: Design parameters corresponding to the prototype structures tested in a previous investigation [29].

\begin{tabular}{|c|c|c|}
\hline \multicolumn{3}{|c|}{ Specimen geometry } \\
\hline$l$ & {$[\mathrm{~m}]$} & 2.0 \\
\hline$h$ & {$[\mathrm{~m}]$} & 0.2 \\
\hline$w$ & {$[\mathrm{~mm}]$} & 125 \\
\hline$d$ & [mm] & 12.9 \\
\hline$t$ & {$[\mathrm{~mm}]$} & 18.0 \\
\hline$c$ & {$[\mathrm{~mm}]$} & 3.0 \\
\hline \multicolumn{3}{|c|}{ Design optimisation } \\
\hline$a$ & {$[-]$} & 0.385 \\
\hline$b$ & {$[-]$} & 0.326 \\
\hline$\varepsilon$ & {$[\mathrm{mm} / \mathrm{m}]$} & 0.56 \\
\hline \multicolumn{3}{|c|}{ Material properties } \\
\hline$f_{c}$ & {$[\mathrm{MPa}]$} & 36.6 \\
\hline$E_{c}$ & {$[\mathrm{GPa}]$} & 27.2 \\
\hline$A_{t}$ & {$\left[\mathrm{~mm}^{2} / \mathrm{m}\right]$} & $65.3 / 52.2^{*}$ \\
\hline$E_{t}$ & {$[\mathrm{GPa}]$} & $64.0 / 55.7^{*}$ \\
\hline$f_{t c}$ & {$[\mathrm{MPa}]$} & $813 / 774^{*}$ \\
\hline
\end{tabular}

\subsection{Discussion}

The model predicts concrete crushing at the corner support, however the observed behaviour of the physical specimens at the ultimate load was more complex. Extensive cracking and deformation occurred across the shell without catastrophic failure at the corner regions. Although the approximate crack locations are indicated correctly in Figure 6, a linear FE model cannot fully capture this behaviour. Instead, the model provides a conservative estimate of strength through a lower-bound approach. In this instance, the proposed model underestimates the experimental failure loads by $21 \%$ and $29 \%$ for the shells with and without fill respectively. Some uncertainty in the prediction would be expected, since the manufacturing errors, non-linear material behaviour and imperfect support conditions of the physical specimens are not captured by the FE model. Each material parameter also has associated variability. Improvements to the model might be made (reducing this conservatism) through more detailed modelling and further physical testing. However, for the purposes of this paper it can be considered a conservative approach. 

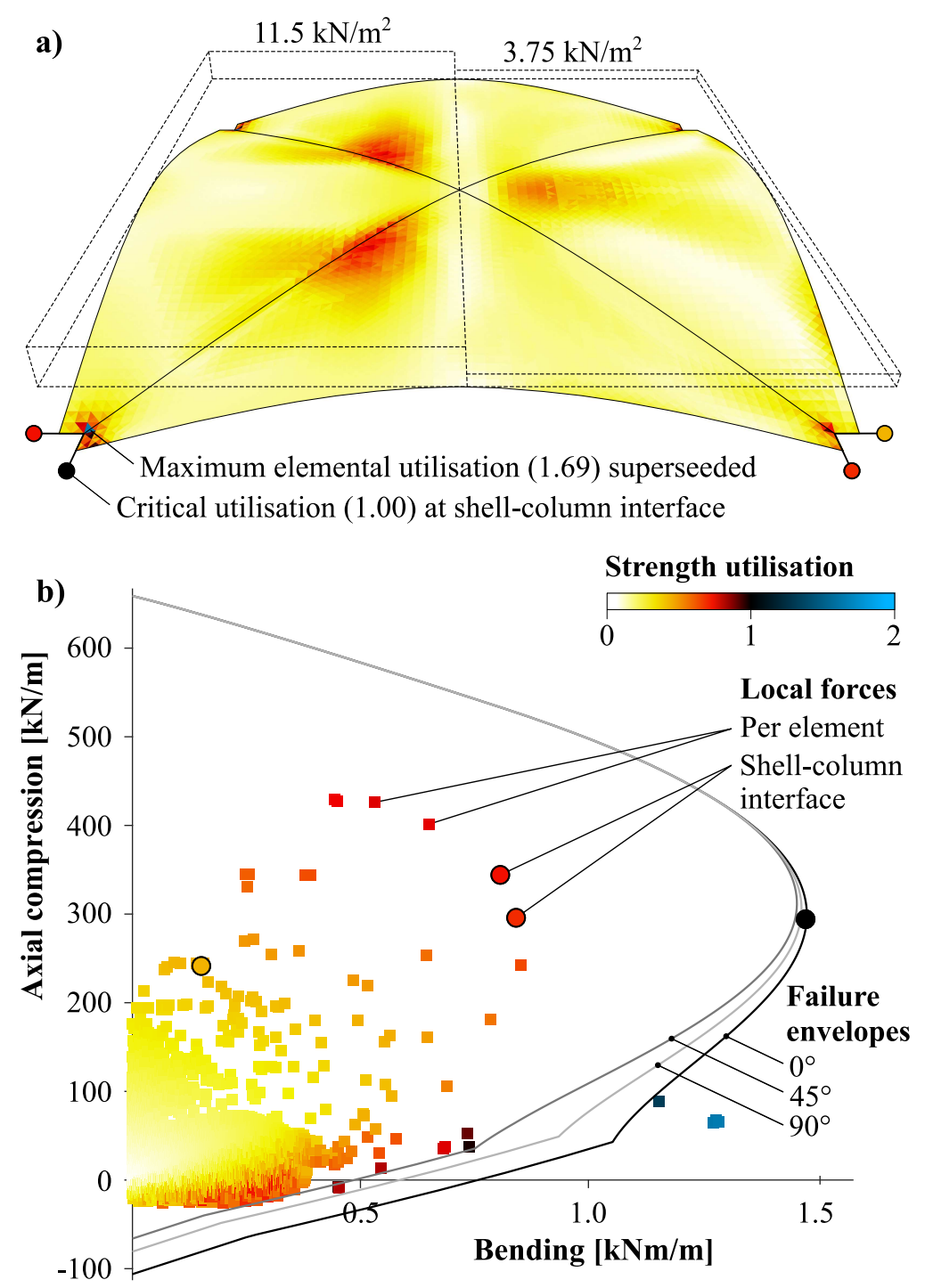

Figure 6: Distribution of strength utilisation at the predicted failure load, for the prototype structures described in Hawkins et al. [29]. Part a) shows the maximum utilisation per element across the shell surface and at each shell-column interface. Part b) plots the corresponding pairs of local axial and bending forces and compares these to the utilisation envelopes for the TRC section.

\section{Design refinement and optimisation}

Using the design methodology now established, this section explores how geometric design parameters including the shell thickness $(t)$, tie diameter $(d)$, depth $(h)$, column width $(w)$ and span $(l)$ influence the structural performance of the system and its embodied carbon. This enables efficient design choices to be made.

\subsection{Material and embodied carbon assumptions}

The concrete strength range considered is $12 \mathrm{MPa} \leq f_{c} \leq 90 \mathrm{MPa}$. In all cases, the Young's modulus (for FE analysis), stress-strain curves (for failure envelope calculation) and tensile strength (for minimum reinforcement using Equation 3) are derived from the compressive strength according to relationships given by BS EN 1992-1-1 [38]. For ULS design, the concrete strength is reduced by a partial factor of 1.5 . 

and embodied carbon calculated by Purnell and Black [19] for mixes featuring 100\% Portland cement binder, using crushed aggregate and without superplasticiser, based on the BRE mix design methodology [44]. Cube strengths have been converted to cylinder strengths using a factor of 0.8 . This was found to give embodied carbon values consistent with other sources in literature [30], and is therefore adopted throughout this paper.

Table 2: Assumed values of density and embodied carbon for each material of the proposed system.

\begin{tabular}{rccc}
\hline Material & $\begin{array}{c}\text { Density } \\
{\left[\mathbf{k g} / \mathbf{m}^{\mathbf{3}}\right]}\end{array}$ & $\begin{array}{c}\text { Embodied } \\
\text { carbon } \\
{[\mathbf{k g C O} \mathbf{e} / \mathbf{k g}]}\end{array}$ & $\begin{array}{c}\text { Embodied carbon } \\
\text { reference }\end{array}$ \\
\hline Fine-grained concrete & 2200 & Figure 7 & Purnell and Black [19] \\
AR-glass textile & 2700 & 3.00 & Granta Design Ltd. [45] \\
Steel ties & 7840 & 1.99 & Jones and Hammond [46] \\
Recycled aggregate (fill) & 1400 & 0.0061 & Jones and Hammond [46] \\
\hline
\end{tabular}

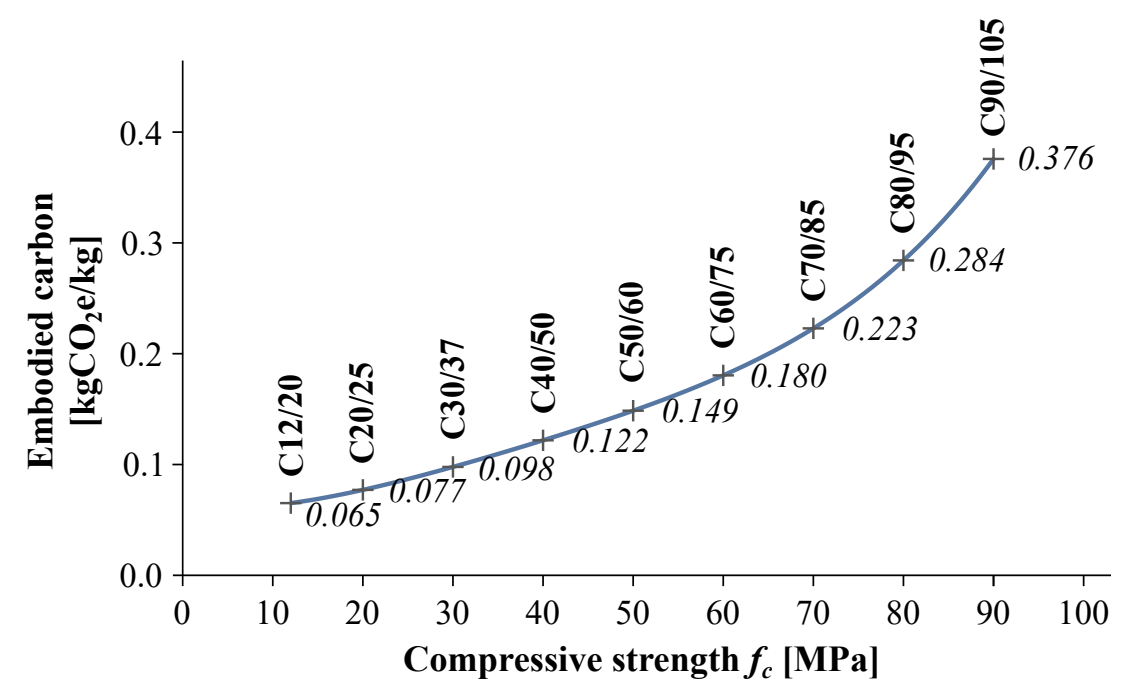

Figure 7: Variation of embodied carbon with concrete compressive strength, from Purnell and Black [19].

\subsection{Influence of shell thickness and tie diameter}

The first investigation determines the influence of shell thickness $(t)$ and tie diameter $(d)$ on total embodied carbon and deflection. A repeatable methodology is then presented which optimises these parameters for any given 
design.

Various combinations of $t$ and $d$ were tested for a fixed span of $l=8 \mathrm{~m}$, depth of $h=800 \mathrm{~mm}$ and column-

235 interface width of $w=500 \mathrm{~mm}$. For each design, the geometric parameters $a$ and $b$ and the pre-strain $\varepsilon$ were optimised (as described in Section 2.2): $a$ and $b$ were set to within \pm 0.005 , which is equivalent to a physical tolerance of approximately $1.6 \mathrm{~mm}$ in this instance, whilst $\varepsilon$ was set to the nearest $0.01 \mathrm{~mm} / \mathrm{m}$. The required area of reinforcement $\left(A_{t}\right)$ and concrete strength $\left(f_{c}\right)$ were then found using the ULS design methodology, and the total embodied carbon calculated. The full details of each design can be found in the research data which supports this publication [47].

Figure 8 shows how the embodied carbon varies across a range of $t$ and $d$ values, and how this is distributed between the concrete, reinforcement, ties and fill. Of these materials, concrete typically makes the greatest contribution. The required concrete strength is inversely correlated with both shell thickness and tie diameter. For the higher values of $t$, the total concrete carbon is therefore approximately constant since increased shell thickness is offset by the lower required strength.

For the majority of designs, the minimum reinforcement area $\left(A_{t, \min }\right)$ was sufficient to provide the required strength throughout the shell, and the reinforcement's contribution to the total embodied carbon is low. The exceptions occur at the lowest tie diameter $(d=30 \mathrm{~mm})$, where the higher bending moments in the shell require $A_{t}$ to be increased above the minimum. The fill volume is approximately constant across all designs, and contributes a maximum of $2.9 \%$ to the total embodied carbon.
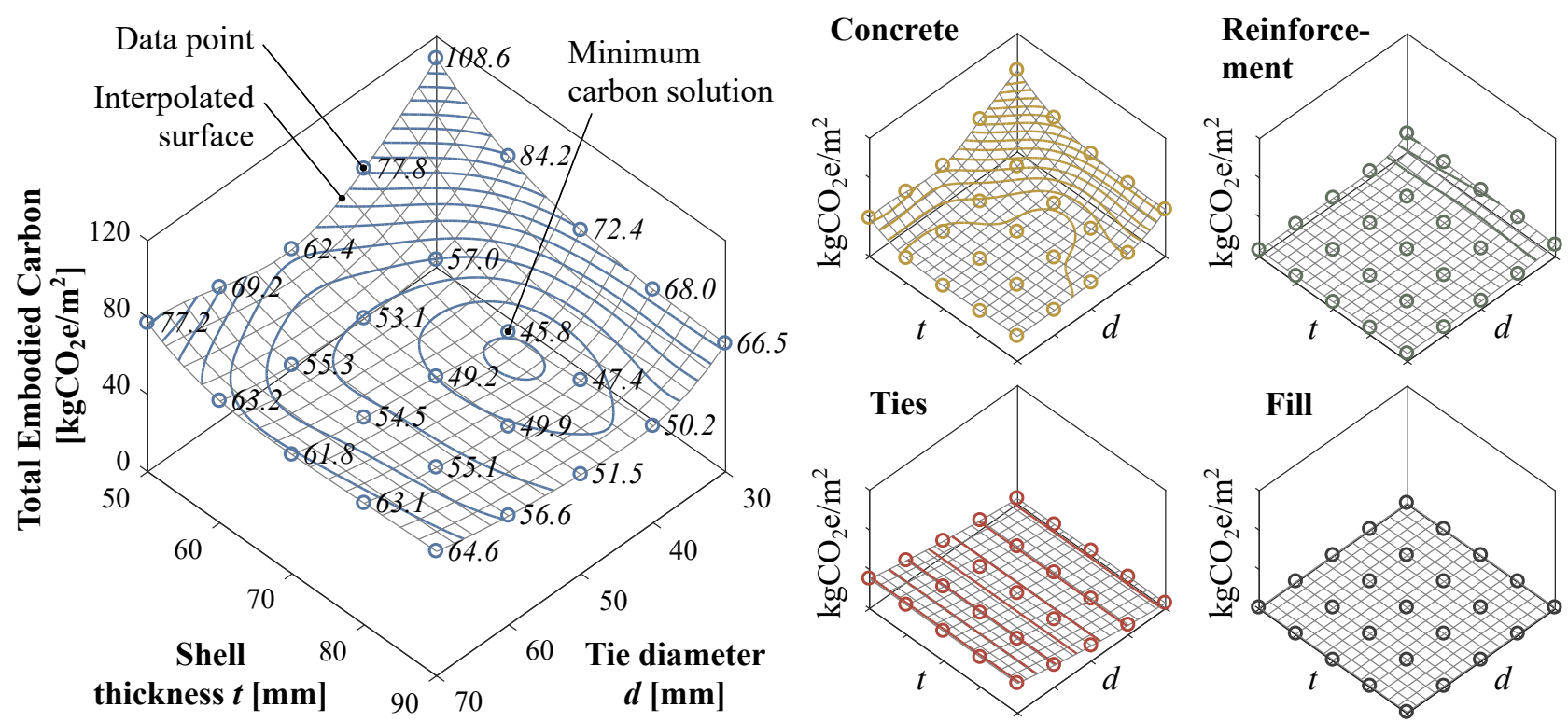

Figure 8: Variation of embodied carbon with shell thickness $(t)$ and tie diameter $(d)$.

The lowest carbon design features a $70 \mathrm{~mm}$ thick shell with $40 \mathrm{~mm}$ diameter ties, and has a total embodied carbon of $45.8 \mathrm{kgCO}_{2} \mathrm{e} / \mathrm{m}^{2}$. The required concrete strength is $f_{c}=46 \mathrm{MPa}$. Near this optimal region, the local variation of embodied carbon is small. For example, increasing the shell thickness to $80 \mathrm{~mm}$ results in only a $3.5 \%$ increase in carbon, due to a corresponding drop in required concrete strength. This is a useful result for design, since optimal parameters can be moderately deviated from without significantly impacting total embodied carbon.

The total $\left(\delta_{\text {total }}\right)$ and live load $\left(\delta_{\text {live }}\right)$ deflections were also calculated for each design using the approach described previously in Section 2.4. In all cases, the long-term dead load deflection $\delta_{1}$ (which includes tie prestress) is upwards, and therefore $\delta_{\text {total }}<\delta_{\text {live }}$. Because of this, only the live load deflection is critical for design. Figure 9 shows how 
$\delta_{\text {live }}$ varies for the ranges of $t$ and $d$ considered.

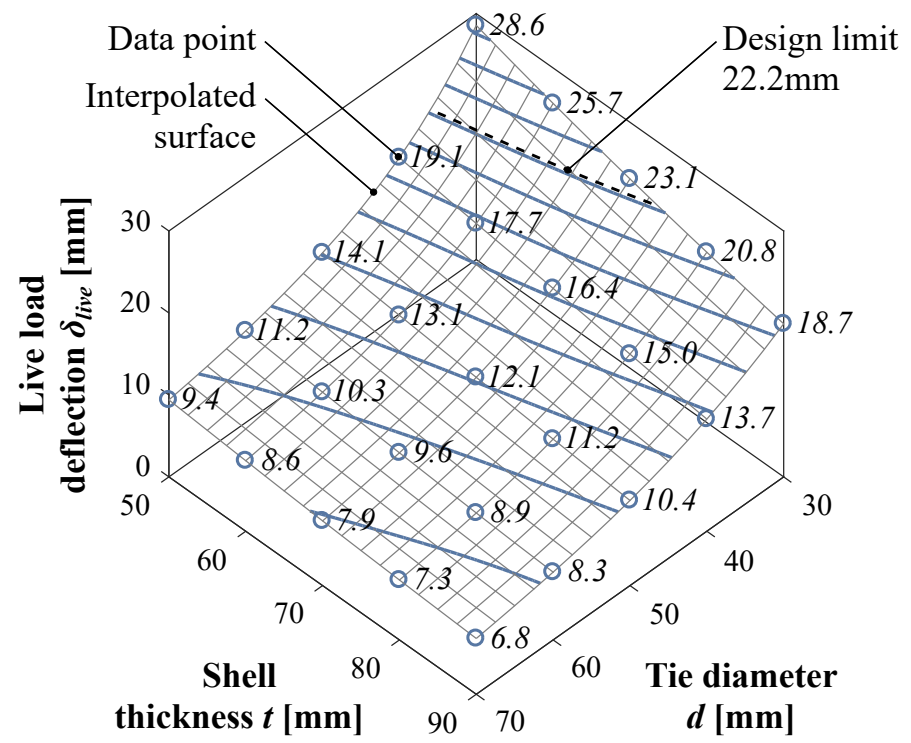

Figure 9: Variation of live load deflection $\delta_{\text {live }}$ with shell thickness $t$ and tie diameter $d$.

All of the designs satisfy the design criteria $(l / 360<22.2 \mathrm{~mm})$, except for the three thinnest shells with the smallest tie diameter. The results show that the deflection is more heavily influenced by the tie diameter than shell thickness. For the lowest carbon design, the live load deflection is $\delta_{\text {live }}=16.4 \mathrm{~mm}$, which is comfortably below the limit. Although the analysis model does not consider the effects of cracking, this would be minimal at serviceability loads [30]. Deflection is, therefore, unlikely to be a concern for efficiently designed shells.

\subsubsection{Optimisation of $t$ and $d$}

A designer wishing to find optimal values of $t$ and $d$ could calculate every design in a given range, as in this investigation, albeit with significant design effort. However, based on the topography of the total embodied carbon surface (Figure 8), a more practical methodology for optimising $t$ and $d$ can be devised.

The optimal shell thickness is approximately constant across all values of tie diameter, and vice versa, near the optimal region. This means that each parameter can potentially be optimised independently in order to simplify the design process.

Figure 10 shows the proposed methodology for determining values of $t$ and $d$ which give a low-carbon design. The thickness $t$ is optimised first, followed by the tie diameter $d$. Although this does not necessarily guarantee that the global minimum embodied carbon is found, any deviation will be small due to the low variation around the optimal region. For each candidate design, the parameters $a, b$ and $\varepsilon$ are re-optimised (as in Section 2.2) to ensure maximum efficiency and a reliable comparison.

A simple optimisation method using uniform increments of $10 \mathrm{~mm}$ is used to find optimal $t$ and $d$ values in the subsequent investigations of this paper. However, since the embodied carbon landscape is smooth and contains a single minimum point, any alternative one-dimensional iterative method could alternatively be used. 


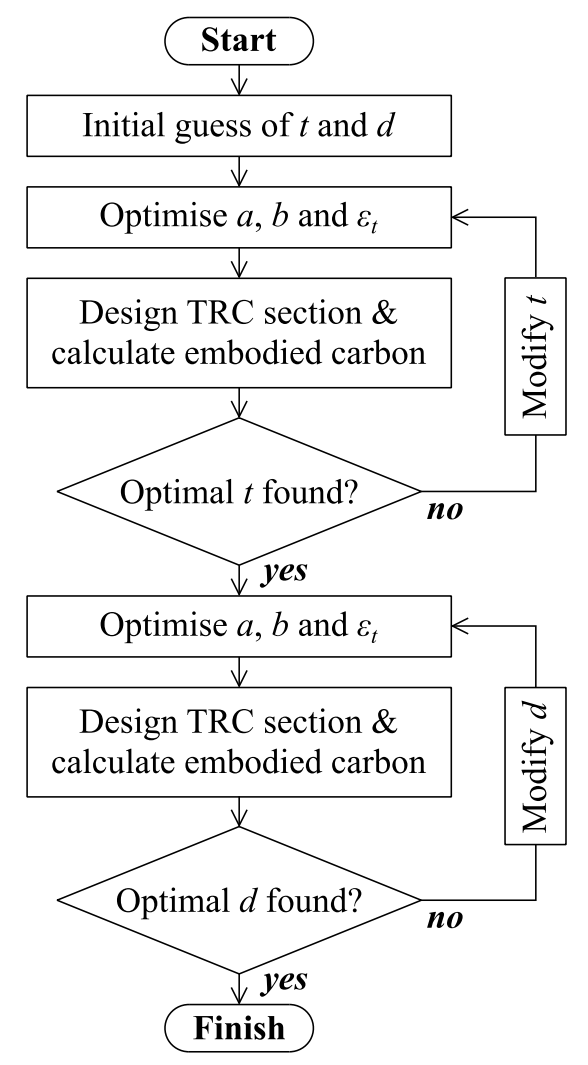

Figure 10: Methodology for determining values of shell thickness $t$ and tie diameter $d$ which give near-optimal designs in terms of embodied carbon.

\subsection{Influence of shell height}

The next investigation determines the influence of shell height $h$ on the structural performance. The height was varied from $400 \mathrm{~mm}$ to $1400 \mathrm{~mm}$, with the span $(l=8 \mathrm{~m})$ and column width $(w=500 \mathrm{~mm})$ kept constant. In each case, optimal values of $t$ and $d$ were found, to the nearest $10 \mathrm{~mm}$, using the approach described in Section 4.2.1. Results including both embodied carbon and self-weight are shown in Figure 11.

There is a negative correlation between shell height and total embodied carbon. This is because an increased height reduces the horizontal thrust from the vault and, correspondingly, the required TRC strength. As for an arch, this effect would be expected to scale as the inverse of $h$ and, accordingly, is most significant at lower heights. Self-weight is typically dominated by the fill (with an exception at $h=400 \mathrm{~mm}$ ) and therefore tends to increase approximately linearly with height. This acts in opposition to the reduced thrust as $h$ increases, leading to diminishing embodied carbon savings at higher values of $h$.

Minimisation of structural depth is often a primary consideration in the design of multi-storey buildings, since this can increase the number of storeys within an available building height. This investigation indicates that $h=800 \mathrm{~mm}$ would be a reasonable design choice in this instance, balancing low structural depth, self-weight and embodied carbon. This gives a span to depth ratio of $l / h=10$, matching that used in the physical prototypes $[29,30]$. The minimum efficient structural depth for the proposed system is likely to be significantly greater than that of an equivalent flat slab, and a more detailed comparison and discussion of this result is made in Section 5.2. 

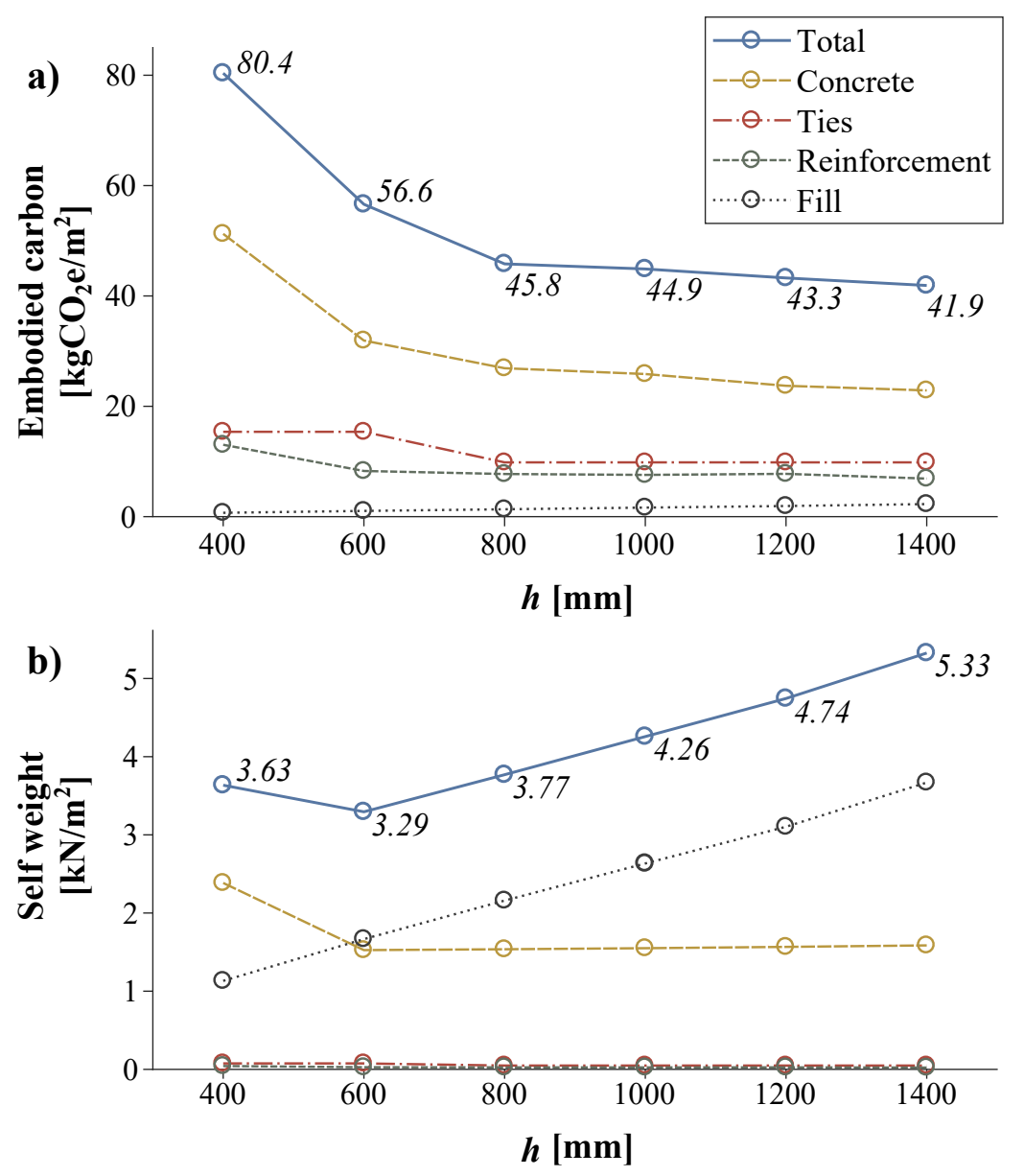

Figure 11: Variation of a) embodied carbon and b) self-weight with shell height $(h)$.

\subsection{Influence of column width}

The shell-column interface is a critical region dictating the required TRC strength, and subsequently the total embodied carbon. The column dimensions in a real building will be influenced by span, loadings, storey-count and architectural intent, so cannot be chosen with only the floor structure in mind. However, a column-head can be provided to ensure efficient operation of the shell if necessary.

An investigation was therefore carried out, varying the column-interface width from $320 \mathrm{~mm}$ to $1600 \mathrm{~mm}$, maintaining a constant span of $l=8 \mathrm{~m}$ and height of $h=800 \mathrm{~mm}$. Again, all other parameters were optimised in each design. Figure 12 shows the resulting distributions of embodied carbon. Variations in self-weight between designs were small.

The results generally show an inverse trend between column-interface width and the embodied carbon of the floor structure. This might be expected, since a smaller column interface concentrates compressive forces into higher stresses. However, the relationship is not smooth, reflecting the complex interaction of force, geometry and materials at this location. For the smallest column sizes, compressive forces are highly concentrated and TRC design is governed by concrete crushing. The critical loading pattern is therefore that which maximises the compressive force: a full uniform load (Pattern 2 in Figure 3). Conversely, for the largest columns, the design is governed by the minimum loading (Pattern 1) where the bending is caused primarily by the tie prestress. Columns of intermediate size result in load Pattern 3 being critical, where bending at the shell-column interface is maximised. Each load 


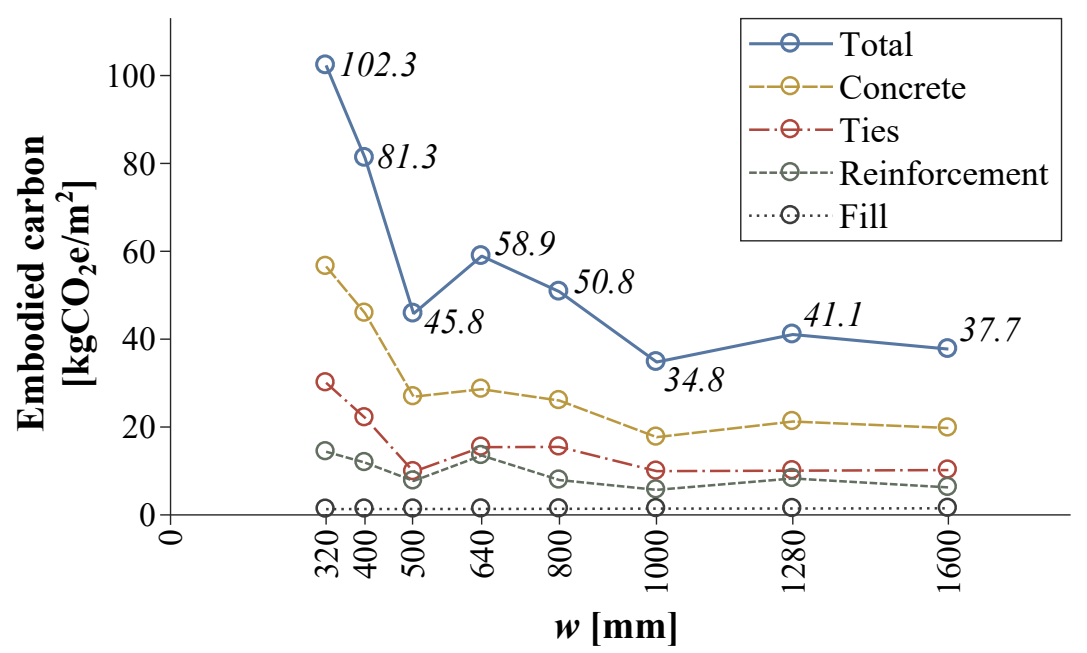

Figure 12: Variation of embodied carbon with column width $w$.

pattern therefore has a unique relationship with column size, creating a non-smooth overall behaviour. The two

column width ratios of $l / w=16$ and $l / w=8$ respectively. No particular load pattern is dominant in these designs, leading to a more efficient solution.

The behaviour at the shell-column interface is complex, and this is reflected in the results of this investigation. This could be explored further in future work, and additional physical testing might also be required to verify that

\subsection{Influence of span}

The final parametric investigation concerns the span $(l)$, which was varied between $6 \mathrm{~m}$ and $18 \mathrm{~m}$. In each case, the shell height $(h)$ and column width $(w)$ were scaled in proportion to span using ratios of $l / h=10$ and $l / w=16$, which were found to give efficient and practical designs in Sections 4.3 and 4.4 respectively. These ratios also match the physical prototypes, and have therefore been verified experimentally [29, 30]. All other design parameters were optimised as in previous investigations.

Each design is summarised in Table 3. The optimal shell thickness and tie diameter increase approximately proportionally to the span, behaviour which is consistent with scaling of a vault acting in pure compression, maintaining constant material stresses [30]. However, the required concrete strength also increases with span. result, the relationship between span and embodied carbon is non-linear, as shown by Figure 13a. As in previous investigations, concrete makes the largest carbon contribution, followed by the ties, reinforcement and fill. In all cases, the minimum reinforcement (Equation 3) is sufficient throughout the shell.

Figure 13b shows a positive correlation between live load deflection $\delta_{\text {live }}$ and span, with reduced increments at between individual designs occurs depending on the chosen value of $d$. The limit of $l / 360$ is never exceeded, and each design is therefore strength governed. 
Table 3: Summary of design parameters for spans between $6 \mathrm{~m}$ and $18 \mathrm{~m}$.

\begin{tabular}{cccccccccc}
\hline $\begin{array}{c}\boldsymbol{l} \\
{[\mathbf{m}]}\end{array}$ & $\boldsymbol{h}=\boldsymbol{l} / \mathbf{1 0}$ \\
{$[\mathbf{m m}]$} & $\boldsymbol{w}=\boldsymbol{l} / \mathbf{1 6}$ & $\begin{array}{c}\boldsymbol{t} \\
{[\mathbf{m m}]}\end{array}$ & $\begin{array}{c}\boldsymbol{d} \\
{[\mathbf{m m}]}\end{array}\left[\begin{array}{c}\boldsymbol{a} \mathbf{m m}] \\
{[-]}\end{array}\right.$ & $\begin{array}{c}\boldsymbol{b} \\
{[-]}\end{array}$ & $\begin{array}{c}\varepsilon_{\boldsymbol{t}} \\
{[\mathbf{m m} / \mathbf{m}]}\end{array}$ & $\begin{array}{c}\boldsymbol{f}_{\boldsymbol{c}} \\
{[\mathbf{M P a}]}\end{array}$ & $\begin{array}{c}\boldsymbol{A}_{\boldsymbol{t}} \\
{\left[\mathbf{m m}^{\mathbf{2}} / \mathbf{m}\right]}\end{array}$ \\
\hline 6 & 600 & 375 & 60 & 30 & 0.455 & 0.370 & 0.94 & 39 & 180 \\
8 & 800 & 500 & 70 & 40 & 0.485 & 0.365 & 1.01 & 46 & 235 \\
10 & 1000 & 625 & 90 & 50 & 0.490 & 0.375 & 1.13 & 47 & 306 \\
12 & 1200 & 750 & 110 & 60 & 0.495 & 0.375 & 1.27 & 49 & 384 \\
14 & 1400 & 875 & 120 & 80 & 0.490 & 0.390 & 1.05 & 54 & 437 \\
16 & 1600 & 1000 & 140 & 90 & 0.500 & 0.395 & 1.16 & 57 & 520 \\
18 & 1800 & 1125 & 170 & 110 & 0.495 & 0.390 & 1.10 & 57 & 632 \\
\hline
\end{tabular}
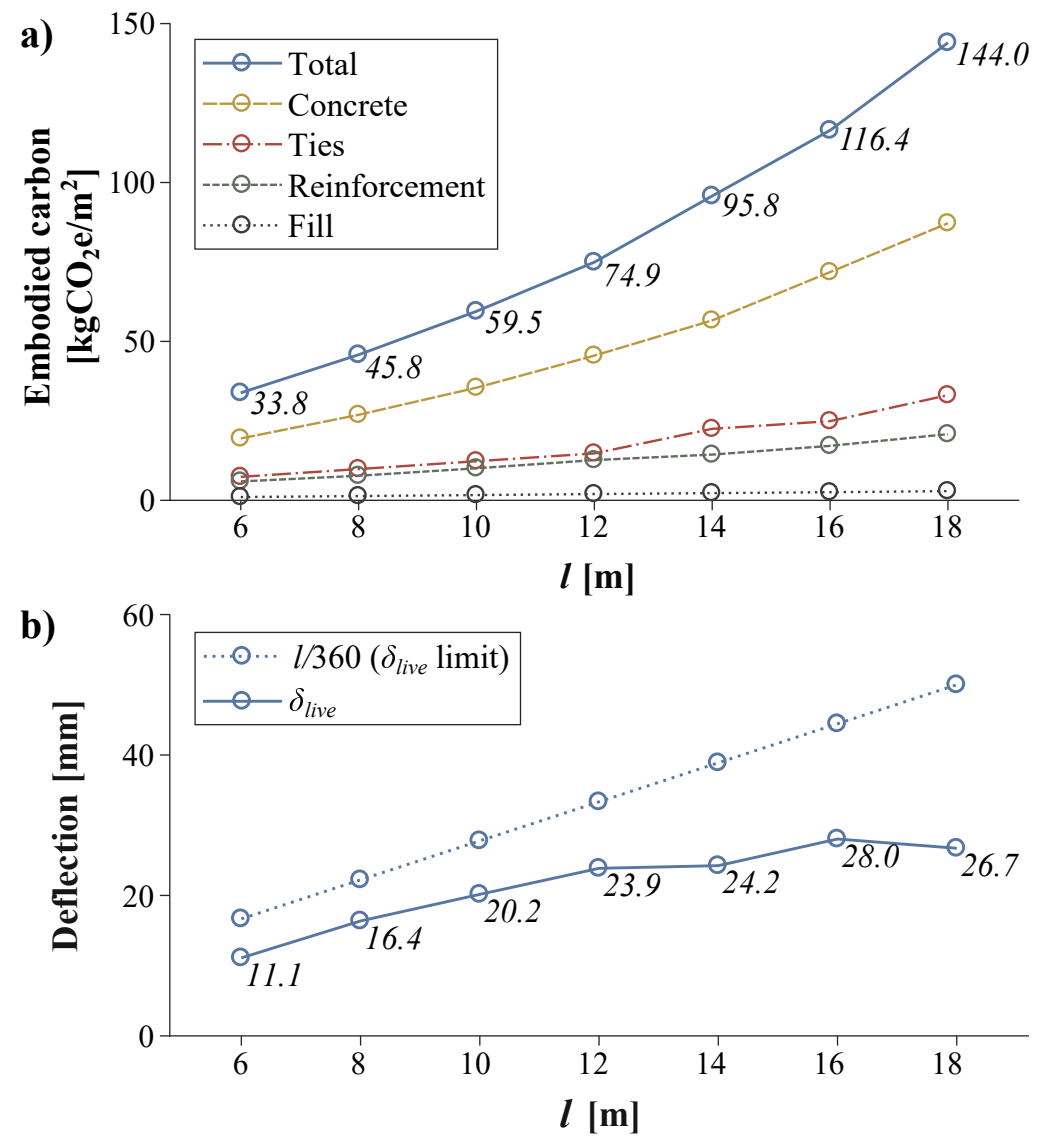

Figure 13: Variation of a) embodied carbon and b) live load deflection $\delta_{\text {live }}$ with span $(l)$, for each design summarised in Table 3.

\section{Comparison with flat slabs}

In the introduction to this paper, it was postulated that the membrane action of thin shells can lead to greater structural efficiency than typical floor structures acting in bending, thereby reducing embodied carbon without sacrificing structural performance. In this section, this is tested by comparing the thin-shell designs given in Table 3 with equivalent flat slabs. 


\subsection{Flat slab design}

Flat slabs must satisfy bending strength, punching shear, deflection and durability requirements. Although often verified using FE analysis, analytical approaches are commonly used where column arrangements are regular. In this example, designs were carried out according to BS EN 1992-1-1 [38], with guidance from a technical report published by the Concrete Society [48]. This was implemented in a spreadsheet and includes the following steps:

1. Initial depth estimate: A span to depth ratio of 24 was assumed.

2. Moment distribution calculation: The equivalent-frame method was employed, which splits the slab into column and middle strips of uniform bending moment. These were calculated assuming a slab situated at the corner of a building. The assumed density of reinforced concrete was $2500 \mathrm{~kg} / \mathrm{m}^{3}$.

3. ULS design: For each slab region, the required reinforcement area was calculated assuming full steel yielding and a rectangular concrete stress distribution. Where necessary, this was increased to the minimum value given by BS EN 1992-1-1, Equation 9.1N [38]. The prescribed steel was then rounded up to the nearest realistic value based on standard bar diameters spaced at $150 \mathrm{~mm}, 175 \mathrm{~mm}$ or $200 \mathrm{~mm}$. Despite this, the average utilisation of steel strength was always above $90 \%$. A concrete cylinder strength of $f_{c}=30 \mathrm{MPa}$ was assumed for all designs, along with a reinforcement yield strength of $500 \mathrm{MPa}$, each reduced by relevant partial factors. The assumed cover was $25 \mathrm{~mm}$.

4. SLS design: A simplified serviceability analysis was used, based on the procedure described in BS EN 19921-1, Section 7.4.2 [38], whereby a maximum ratio of span to effective depth is calculated as a function of the concrete strength and the mid-span reinforcement. The slab depth was minimised, whilst satisfying this requirement, in all cases. This reflects typical design practice for a tall building, and the slab depth is therefore governed by serviceability criteria. Where necessary, Steps 2 and 3 were repeated until the lowest suitable depth was found, to the nearest $10 \mathrm{~mm}$.

The outcome of this approach is that the slab depth is largely dictated by SLS requirements, and the reinforcement quantity by ULS requirements. Compared to a buildable design, several simplifications are made, likely leading to an underestimate of realistic reinforcement quantities. Laps between bars have been ignored, as well as punching shear reinforcement at columns. In a real design, rationalisation of bar sizes and spacings would also increase the total steel quantity.

Table 4 summarises the resulting flat slab designs. Embodied carbon was calculated using material values of $0.098 \mathrm{kgCO}_{2} \mathrm{e} / \mathrm{kg}$ for $\mathrm{C} 30 / 37$ concrete and $1.99 \mathrm{kgCO}_{2} \mathrm{e} / \mathrm{kg}$ for steel reinforcement, matching those used previously in the thin-shell designs.

Table 4: Flat slab design parameters and embodied carbon for spans of $6 \mathrm{~m}$ to $18 \mathrm{~m}$.

\begin{tabular}{|c|c|c|c|c|c|}
\hline \multicolumn{3}{|c|}{ Design } & \multicolumn{3}{|c|}{ Embodied carbon } \\
\hline $\begin{array}{c}\text { Span } \\
{[\mathbf{m}]}\end{array}$ & $\begin{array}{c}\text { Slab } \\
\text { thickness } \\
{[\mathbf{m m}]} \\
\end{array}$ & $\begin{array}{c}\text { Reinforcement } \\
\text { quantity } \\
{\left[\mathbf{k g} / \mathbf{m}^{3}\right]}\end{array}$ & $\begin{array}{r}\text { Concrete } \\
{[\mathrm{k}} \\
\end{array}$ & $\begin{array}{l}\text { Steel } \\
\mathrm{CO}_{2} \mathrm{e} / \\
\end{array}$ & Total \\
\hline 6 & 220 & 59.7 & 51.6 & 26.1 & 77.8 \\
\hline 8 & 300 & 64.1 & 70.4 & 38.3 & 108.7 \\
\hline 10 & 360 & 69.6 & 84.5 & 49.8 & 134.3 \\
\hline 12 & 450 & 74.9 & 105.6 & 67.1 & 172.7 \\
\hline 14 & 550 & 81.6 & 129.1 & 89.3 & 218.4 \\
\hline 16 & 630 & 88.1 & 147.9 & 110.4 & 258.3 \\
\hline 18 & 760 & 83.2 & 178.4 & 125.0 & 303.4 \\
\hline
\end{tabular}




\subsection{Performance comparison}

Figure 14 compares the embodied carbon, self-weight and depth of the proposed thin-shell system with an equivalent flat slab. By switching from slabs to shells, the embodied carbon is reduced significantly and consistently across all spans, by between $53 \%$ and $58 \%$. Self-weight savings are also considerable, and increase from $43 \%$ to $53 \%$ with increasing span. This would be expected to reduce column and foundation loads, particularly for tall buildings, potentially leading to additional material savings across the building.
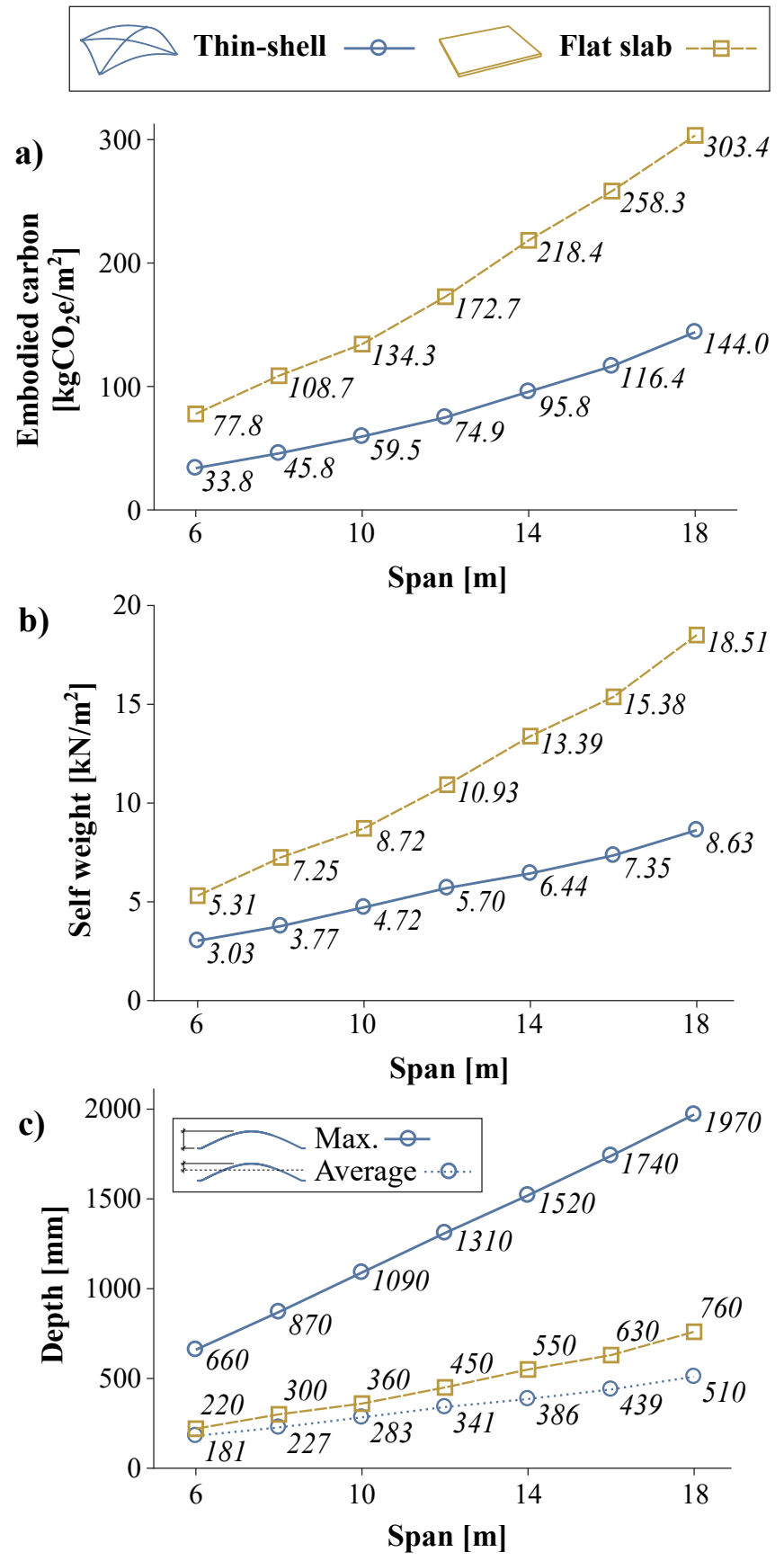

Figure 14: Comparison between the proposed thin-shell flooring system an equivalent flat slab for variable spans, including a) embodied carbon, b) self weight and c) depth. 
The thin-shell flooring system has a considerably larger maximum structural depth across all spans. This

reduction in alkalinity would also improve the durability of AR-glass or basalt reinforcement [52].

The vibration and acoustic performance of the system is yet to be considered in detail, although it is hypothesised that the use of a granular fill would be advantageous in both regards. Fire performance must also be thoroughly assessed before implementation in real building projects.

Simplicity of construction was considered at the outset for the proposed system, and was demonstrated by the successful construction of hand-built prototypes [29, 30]. At full-scale, sprayed concrete could be used to manufacture the shells rapidly. This technique has previously been used to create large TRC shells with multiple layers of reinforcement [53], and could be automated by attaching a spraying nozzle to a movable gantry to maximise consistency and accuracy. 


\section{Conclusions}

This paper set out to explore the potential of thin-shells as a practical and low-carbon alternative to typical concrete floors, switching the principal mechanism of load resistance from bending to membrane action. A system was proposed consisting of pre-cast TRC groin-vaults with prestressed steel ties and a non-structural fill material. A complete design methodology has been presented, building upon previous theoretical and experimental work, allowing the behaviour and performance of the proposed system to be explored in detail. A series of parametric investigations have been carried out, leading to refinement of the design. The proposed thin-shell system was then compared to equivalent reinforced concrete flat slabs, for a typical UK office design scenario with spans of 6-18 m.

Key conclusions of these investigations include:

- The shell-column interface, where compressive forces are concentrated, is a critical region governing the required shell thickness and concrete strength.

- The proposed design methodology gives a conservative estimate of strength, based on comparisons with physical test specimens.

- The variation of total embodied carbon is low across a range of shell thicknesses and tie diameters, enabling simple generation of near-optimal designs. Similarly, the effect of shell height on total embodied carbon is small, providing the span to depth ratio is above a threshold value (of $l / h=10$ in this instance).

- The design of the proposed thin-shell system is strength-governed at all spans, with long-term deflections always below typical design limits. This points to efficient use of materials, at their full capacity, and contrasts with typical concrete floors where serviceability dictates slab depth.

- Compared to equivalent flat slabs, the proposed thin-shell system offers significant embodied carbon reductions across a wide range of spans, of $53 \%$ to $58 \%$. It is also $43 \%$ to $53 \%$ lighter, potentially leading to further savings in columns and foundations.

This paper has shown that thin concrete shells are feasible and efficient floor structures. The proposed system and design methodology provide a robust platform for further refinement and full-scale implementation, offering a practical means by which structural engineers can significantly reduce the carbon footprint of buildings.

\section{Acknowledgements}

This research was supported by the EPSRC Centre for Decarbonisation of the Built Environment (dCarb) [grant number EP/L016869/1], the Building Research Establishment (BRE) Trust and the University of Cambridge Department of Engineering.

\section{Data access statement}

The data created in this research is openly available from the University of Cambridge data repository at https://doi.org/10.17863/CAM.44020. 


\section{References}

[1] U.S. Geological Survey, Mineral commodity summaries, 2018. www.usgs.gov/centers/nmic/ mineral-commodity-summaries (accessed June 2019).

[2] J. Lehne, F. Preston, Making Concrete Change: Innovation in Low-carbon Cement and Concrete, Chatham House Reports, 2018.

[3] T. Boden, R. Andres, G. Marland, Global co2 emissions from fossil-fuel burning, cement manufacture, and gas flaring: 1751-2014, Oak Ridge National Laboratory, 2017.

[4] I. E. A. IEA, Energy Technology Perspectives 2008: Scenarios \& Strategies to 2050, OECD/International Energy Agency, 2008.

[5] T. Wang, D. B. Müller, T. Graedel, Forging the anthropogenic iron cycle, Environmental science \& technology 41 (2007) 5120-5129.

[6] W. Shanks, C. Dunant, M. P. Drewniok, R. Lupton, A. Serrenho, J. M. Allwood, How much cement can we do without? lessons from cement material flows in the uk, Resources, Conservation and Recycling 141 (2019) 441 - 454. doi:https://doi.org/10.1016/j.resconrec.2018.11.002.

[7] J. M. Cullen, J. M. Allwood, M. D. Bambach, Mapping the global flow of steel: From steelmaking to end-use goods, Environmental science \& technology 46 (2012) 13048-13055.

[8] T. Abergel, B. Dean, J. Dulac, Towards a zero-emission, efficient, and resilient buildings and construction sector: Global Status Report 2017, Technical Report, UN Environment and International Energy Agency, 2017.

[9] J. M. Allwood, M. F. Ashby, T. G. Gutowski, E. Worrell, Material efficiency: A white paper, Resources, Conservation and Recycling 55 (2011) 362-381.

[10] P. Griffin, G. Hammond, J. Norman, Prospects for emissions reduction in the uk cement sector, Proceedings of Institution of Civil Engineers: Energy 167 (2014) 152-161. doi:10.1680/ener.14.00007.

475 [11] UK strucutral engineers declare climate \& biodiversity emergency, Online, 2019. URL: www. structuralengineersdeclare.com.

[12] C. De Wolf, M. Ramage, J. Ochsendorf, Low carbon vaulted masonry structures, Journal of the International Association for Shell and Spatial Structures (2016).

[13] P. Foraboschi, M. Mercanzin, D. Trabucco, Sustainable structural design of tall buildings based on embodied energy, Energy and Buildings 68 (2014) 254-269.

[14] J. Orr, M. P. Drewniok, I. Walker, T. Ibell, A. Copping, S. Emmitt, Minimising energy in construction: Practitioners' views on material efficiency, Resources, Conservation and Recycling 140 (2019) 125 - 136. doi:https://doi.org/10.1016/j.resconrec.2018.09.015.

[15] D. Miller, J.-H. Doh, M. Mulvey, Concrete slab comparison and embodied energy optimisation for alternate design and construction techniques, Construction and Building Materials 80 (2015) 329-338. 
[16] C. T. Griffin, B. Reed, S. Hsu, Comparing the embodied energy of structural systems in buildings, in: Proceedings of the 1st International Conference on Structures and Architecture, ICSA 2010, 2010, pp. 13671373.

[17] A. Ockleston, Arching action in reinforced concrete slabs, The Structural Engineer 36 (1958) 197-201.

[18] S. May, H. Michler, F. Schladitz, M. Curbach, Lightweight ceiling system made of carbon reinforced concrete, Structural Concrete 19 (2018). doi:10.1002/suco.201700224.

[19] P. Purnell, L. Black, Embodied carbon dioxide in concrete: Variation with common mix design parameters, Cement and Concrete Research 42 (2012) 874-877.

[20] S. Das, Life cycle assessment of carbon fiber-reinforced polymer composites, The International Journal of Life Cycle Assessment 16 (2011) 268-282. doi:https://doi.org/10.1007/s11367-011-0264-z.

[21] A. Liew, D. L. López, T. Van Mele, P. Block, Design, fabrication and testing of a prototype, thin-vaulted, unreinforced concrete floor, Engineering Structures 137 (2017) 323-335.

[22] D. L. López, D. Veenendaal, M. Akbarzadeha, P. Block, Prototype of an ultra-thin, concrete vaulted floor system, in: IASS-SLTE 2014 Symposium, Brasilia, 2014.

[23] I. Agustí-Juan, G. Habert, Environmental design guidelines for digital fabrication, Journal of Cleaner Production 142 (2017) 2780 - 2791. doi:https://doi.org/10.1016/j.jclepro.2016.10.190.

[24] J. Ochsendorf, Guastavino vaulting: The art of structural tile, Princeton Architectural Press, 2010.

[25] P. Block, M. DeJong, L. Davis, J. Ochsendorf, Tile vaulted systems for low-cost construction in africa, Journal of the African Technology Development Forum (ATDF) 7 (2010) 4-13.

[26] L. Davis, Building the sudu, Online, 2010. URL: http://sudu1construction.wordpress.com/.

[27] W. Hawkins, J. Orr, P. Shepherd, T. Ibell, J. Bregulla, Thin-shell textile-reinforced concrete floors for sustainable buildings, in: IASS Annual Symposium 2017, Hamburg, 2017.

[28] W. Hawkins, J. Orr, T. Ibell, P. Shepherd, An analytical failure envelope for the design of textile reinforced concrete shells, Structures 15 (2018) 56-65.

${ }_{510}[29]$ W. Hawkins, J. Orr, P. Shepherd, T. Ibell, Design, construction and testing of a low carbon thin-shell concrete flooring system, Structures 18 (2019) 60-71. doi:https://doi.org/10.1016/j.istruc.2018.10.006.

[30] W. Hawkins, Thin-shell concrete floors for sustainable buildings, Ph.D. thesis, University of Cambridge, 2019. doi:https://doi.org/10.17863/CAM. 45976.

[31] E. P. Kearsley, P. J. Wainwright, The effect of porosity on the strength of foamed concrete, Cement and Concrete Research 32 (2002) 233-239. URL: http://www.sciencedirect.com/science/article/pii/ S0008884601006652.

[32] P. J. Tikalsky, J. Pospisil, W. MacDonald, A method for assessment of the freeze-thaw resistance of preformed foam cellular concrete, Cement and concrete research 34 (2004) 889-893.

[33] C. Preisinger, Linking structure and parametric geometry, Architectural Design 83 (2013) 110-113. 
520 [34] BSI, Eurocode 1: Actions on structures (BS EN 1991-1-1:2005) Part 1-1: General actions - Densities, self-weigh, imposed loads for buildings, British Standards Institution, 2002.

[35] L. Clarke, R. Cope, Concrete slabs: analysis and design, CRC Press, 1984.

[36] S. P. Timoshenko, S. Woinowsky-Krieger, Theory of plates and shells, McGraw-hill, 1959.

[37] G. Couchman, D. Mullett, J. Rackham, Composite slabs and beams using steel decking: Best practice for design and construction, SCI PUBLICATION (2000).

[38] BSI, Eurocode 2: Design of concrete structures, British Standards Institution, 2004.

[39] A. Scholzen, R. Chudoba, J. Hegger, Thin-walled shell structures made of textile-reinforced concrete: Part ii, Structural Concrete 16 (2015) 115-124.

[40] J. Hegger, N. Will, O. Bruckermann, S. Voss, Load-bearing behaviour and simulation of textile reinforced concrete, Materials and structures 39 (2006) 765-776.

[41] M. D. Kotsovos, A fundamental explanation of the behaviour of reinforced concrete beams in flexure based on the properties of concrete under multiaxial stress, Matériaux et Construction 15 (1982) 529. URL: https: //doi.org/10.1007/BF02473698.

[42] T. Ibell, C. Burgoyne, A generalized lower-bound analysis of anchorage zones, Magazine of Concrete Research 46 (1994) 133-144.

[43] S. Scheerer, R. Chudoba, M. P. Garibaldi, M. Curbach, Shells made of textile reinforced concrete-applications in germany, Journal of the international association for shell and spatial structures 58 (2017) 79-93.

[44] D. C. Teychenné, R. E. Franklin, H. C. Erntroy, B. Marsh, Design of normal concrete mixes, 2nd edition, Building Research Establishment Ltd, Garston, UK, 1997.

540 [45] Granta Design Ltd., The Cambridge Engineering Selector EduPack 2018 Version 18.1.1, Granta Design, 2018. www.grantadesign.com/industry/products/ces-selector/ (accessed June 2019).

[46] C. Jones, G. Hammond, Inventory of carbon \& energy Version 3.0 (ICE V3.0), Department of Mechanical Engineering, University of Bath, UK (2019).

[47] W. Hawkins, J. Orr, T. Ibell, P. Shepherd, Research data supporting 'A design methodology to reduce the 545 embodied carbon of concrete buildings using thin-shell floors', 2020. doi:https://doi.org/10.17863/CAM . 44020 .

[48] Concrete Society, Technical report no. 64: Guide to the design and construction of reinforced concrete flat sabs, CCIP-022 (2007).

[49] S. Kaethner, J. Burridge, Embodied CO2 of structural frames, The structural engineer 90 (2012) 33-40.

${ }_{550}$ [50] E. Sharei, A. Scholzen, J. Hegger, R. Chudoba, Structural behavior of a lightweight, textile-reinforced concrete barrel vault shell, Composite Structures 171 (2017) 505-514.

[51] N. Williams-Portal, K. Lundgren, H. Wallbaum, K. Malaga, Sustainable potential of textile-reinforced concrete, Journal of Materials in Civil Engineering 27 (2014). 
[52] M. Butler, V. Mechtcherine, S. Hempel, Durability of textile reinforced concrete made with ar glass fibre: effect of the matrix composition, Materials and structures 43 (2010) 1351-1368.

[53] A. Scholzen, R. Chudoba, J. Hegger, Thin-walled shell structures made of textile-reinforced concrete: Part i, Structural Concrete 16 (2015) 106-114. 